\title{
Nano-clays from natural and modified montmorillonite with and without added blueberry extract for active and intelligent food nanopackaging materials
}

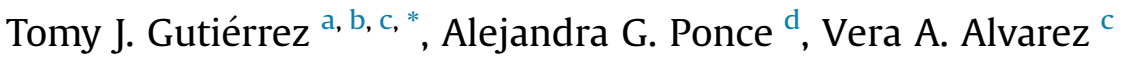 \\ ${ }^{a}$ Departamento Químico Analítico, Facultad de Farmacia, Universidad Central de Venezuela, Apartado 40109, Caracas, 1040-A, Venezuela \\ ${ }^{\mathrm{b}}$ Instituto de Ciencia y Tecnología de Alimentos, Facultad de Ciencias, Universidad Central de Venezuela, Apartado 47097, Caracas, 1041-A, Venezuela

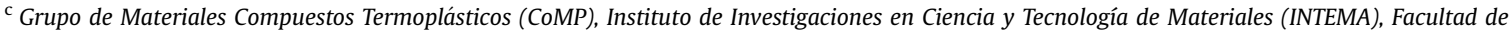 \\ Ingeniería, Universidad Nacional de Mar del Plata (UNMdP) y Consejo Nacional de Investigaciones Científicas y Técnicas (CONICET), Colón 10850, B7608FLC, \\ Mar del Plata, Argentina \\ ${ }^{\mathrm{d}}$ Grupo de Investigación en Ingeniería en Alimentos, Facultad de Ingeniería, Universidad Nacional de Mar del Plata (UNMdP), Juan B. Justo 4302, 7600, Mar \\ del Plata, Argentina
}

\section{H I G H L I G H T S}

- Food nano-packaging were obtained from natural and modified montmorillonite (Mnt).

- XRD, TGA and FTIR results suggests the blueberry extract nanopackaging.

- Intelligent nanocomposites were obtained.

- Greater interlayer spacing of the nano-Mnt allows greater nanopackaging.

\section{A R T I C L E I N F O}

\section{Article history:}

Received 19 January 2017

Received in revised form

24 March 2017

Accepted 28 March 2017

Available online 30 March 2017

\section{Keywords:}

Composite materials

Nanostructures

Fourier transform infrared spectroscopy (FTIR)

Thermogravimetric analysis (TGA)
G R A P H I C A L A B S T R A C T

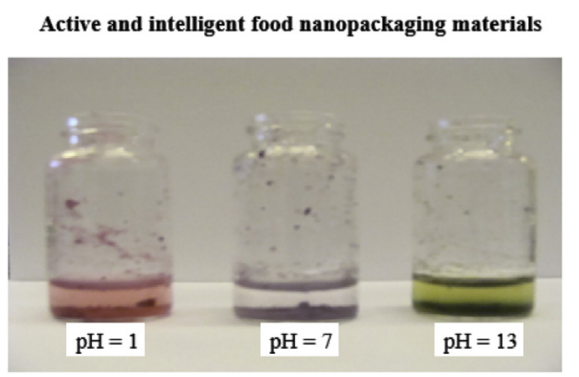

\begin{abstract}
A B S T R A C T
The aim of this study was to evaluate the potential of nano-clays as active and intelligent (A\&I) food nanopackaging materials. Nanopackaging is a structured system that allows the storage of certain compounds in a stable form. Nano-clays were prepared from natural and modified montmorillonite (Mnt) with and without added blueberry extract, and characterized in terms of their: X-ray diffraction (XRD) patterns, thermogravimetric (TGA) properties, microstructure, moisture content, water activity $\left(a_{w}\right)$, infrared spectra (FTIR), Raman spectra, color parameters, response to $\mathrm{pH}$ changes, and antioxidant and antimicrobial activity. Mnt prepared with added blueberry extract showed antioxidant activity and intelligent behavior under different $\mathrm{pH}$ conditions. Modifying the Mnt increased the interlayer spacing, thus allowing more blueberry extract to be incorporated within the system. In conclusion, natural and modified Mnt are eco-friendly resources with potential applications for nano-packaging. The addition of blueberry extract imparted intelligent properties to the nano-clays as regards their responses to changes in $\mathrm{pH}$.
\end{abstract}

(c) 2017 Elsevier B.V. All rights reserved.

\footnotetext{
* Corresponding author. Instituto de Ciencia y Tecnología de Alimentos, Facultad de Ciencias, Universidad Central de Venezuela, Apartado 47097, Caracas, 1041-A, Venezuela.

E-mail addresses: tomy.gutierrez@ciens.ucv.ve, tomy_gutierrez@yahoo.es (T.J. Gutiérrez).
}

\section{Introduction}

Montmorillonite (Mnt), a member of the smectite group, is one of the clay minerals most commonly utilized as nanocomposites 
and accounts for nearly $70 \%$ of the clay market volume [1,2]. Clay is a naturally abundant, toxin-free mineral used in foods, medicines, cosmetics, and healthcare products [3] as well as being environmentally friendly and inexpensive.

Clays and clay minerals are technologically important materials mainly composed of hydrated aluminosilicate with neutral or negative charged layers [4]. Layered silicates typically have a stacked arrangement of silicate layers (platelets) held apart principally by electrostatic forces. Platelets are only $1 \mathrm{~nm}$ thick but have a huge surface area (over $750 \mathrm{~m}^{2} / \mathrm{g}$ ) and aspect ratios ranging from 100 to $500[1,5,6]$. Each layer is characterized by a $2: 1$ structure with a central octahedral sheet of alumina attached to two external tetrahedral sheets of silica [7-9]. The net negative charge of the layers, generated due to isomorphic substitutions of $\mathrm{Al}^{+3}$ with $\mathrm{Fe}^{+2}$ or $\mathrm{Mg}^{+2}$ in the octahedral sites and of $\mathrm{Si}^{+4}$ with $\mathrm{Al}^{+3}$ in the tetrahedral sites, is compensated by the presence of cations, mainly $\mathrm{Na}^{+}$ and $\mathrm{Ca}^{+2}$, situated in the interlayer space [10]. The presence of inorganic cations between the planar surfaces of the Mnt layers is what gives these clays their hydrophilic character.

Clays have been modified for different purposes by replacing these inorganic cations with organic ones through cation exchange reactions. Organic cations employed in this way are mostly surfactants, such as ammonium salts, which increase the interlayer spacing and surface hydrophobicity [5,11]. Modified clays prepared by cation exchange with long-chain quaternary alkylammonium or phosphonium salts have been widely studied and the resulting organoclays used in the preparation of nanocomposites, mainly for industrial applications $[12,13]$. In recent years, however, the use of these clays has been extended to other fields including drug delivery systems [14-17], the production of excipient and active substances in pharmaceutical products $[18,19]$ and antithrombogenic materials [20], and the immobilization of hosts for biological species such as enzymes, amino acids, proteins, nucleic acids, and phospholipids [12,21-26]. Nonetheless, organoclays have been little studied as food nano-packaging materials compared to other nano-encapsulation systems [27].

According to Bracone et al. [27], the term nano-packaging refers to nanostructured materials that package certain compounds of interest. In this context, clay minerals have been developed and used especially in food and drug nanopackaging. These clay mineral-based systems, as mentioned above, allow the controlled release of drugs and prevent oxidative damage in foods, thus reducing food loss. Despite their importance, however, clay mineral systems have been poorly studied.

With this in mind, a nano-packaging system could be developed by incorporating blueberry extract in the silicate interlayer spaces of clay, i.e. between the silicate layers $[6,28]$. Blueberries contain anthocyanins which change color under different $\mathrm{pH}$ due to a shift in their molecular structure from a quinoidal to a flavylium form [29]. The addition of blueberry extract could thus transform these clays into active and intelligent nanocomposites that respond to changes in $\mathrm{pH}$.

These active and intelligent materials derived from eco-friendly resources could be used to produce food nano-packaging that provides consumers with information about the quality and safety of food products. Changes in the coloration of the packaging could be associated with the fraudulent modification of foods, noncompliance of the cold chain, or simply alert consumers to the freshness of the food [30,31]. In this regard, the FAO [32] has estimated that approximately a third of the food produced annually for human consumption is wasted. This represents a loss of about 1.3 billion tons of food, valued at over USD 750 billion, which could feed the more than 842 million of people that still suffer from chronic hunger globally [33]. The incorporation of blueberry extract could, furthermore, enable the production of bioactive compounds that have a favorable impact on the prevention of diseases such as cancer [34] and kidney infections [35].

The goal of this research was to develop nano-clays with potential uses for active and intelligent food nanopackaging. In order to achieve this the physical and chemical properties of two nanoclays derived from Mnt, one natural, and the other modified with a quaternary ammonium salt (dimethyl dehydrogenated tallow ammonium), were analyzed. Nanocomposites prepared from the clays plus blueberry extract were also investigated.

\section{Experimental}

\subsection{Materials}

The clays evaluated in this study were natural and modified montmorillonites (Mnt) supplied by Laviosa Chimica Mineraria S.p.A. (Livorno, Italy), and were used as received. According to the manufacturer's instructions, the modified Mnt is a nanoclay derived from a naturally occurring Mnt, purified and modified with a quaternary ammonium salt (dimethyl dehydrogenated tallow ammonium). This modification was selected based on the fact that it has been well known in the literature for years, and the resulting modified clay is nontoxic with no risk to human health [36-38]. The cation exchange capacity (CEC) of natural Mnt, measured by the methylene blue method, gave a CEC of $105 \mathrm{meq} / 100 \mathrm{~g}$ clay. Blueberry (Vaccinium corymbosum) extract was obtained according to the methodology proposed by Dai et al. [39] using ethanol as a solvent, since it maintains the properties of blueberries. According to Dai et al. [39] the chemical composition of blueberry extract is $100 \%$ anthocyanin. Ripe fruits were purchased from a local market in Mar del Plata, Buenos Aires, Argentina. The fruits were selected, discarding any diseased or stained specimens, before weighing out $170 \mathrm{~g}$, crushing and filtering. The residue obtained, mainly the fruit skin, was then washed with $100 \mathrm{~mL}$ of ethanol (Aldrich: product code: 34923 ). Interestingly, this type of waste is normally produced by manufacturing processes during the preparation of filtered blueberry juices. The blueberry extract was prepared the same day the clays were developed, and maintained refrigerated at $5{ }^{\circ} \mathrm{C}$ in a dark container until further processing in order to avoid oxidative damages.

\subsection{Formation of the nano-clays}

The nano-clays were prepared by mixing $2 \mathrm{~g}$ of clay and $40 \mathrm{~mL}$ of blueberry extract. The mixture was then frozen at $-20^{\circ} \mathrm{C}$ for $48 \mathrm{~h}$ after which it was lyophilized at $100 \mathrm{mTorr}$ and $-50{ }^{\circ} \mathrm{C}$ for $72 \mathrm{~h}$ using a Gland type Vacuum Freeze Dryer, Columbia International, Model FD-1B-50 (Shaan Xi, China) in order to obtain a free flowing product. Lyophilization also preserves the active compounds of the blueberry extract and ensures a size of clay particle in the nanometer range. The resultant clays were conditioned in containers with a saturated solution of $\mathrm{NaBr}\left(a_{w} \sim 0.575\right.$ at $\left.25^{\circ} \mathrm{C}\right)$ for seven days prior to each test. During this period the containers were protected from light in a dark room to avoid photodegradation of the antioxidant compounds and pigments. Samples used to determine the water activity $\left(a_{w}\right)$ of the clays were not conditioned. Four types of clay samples were prepared as follows: natural montmorillonite (NMnt), natural montmorillonite with added blueberry extract (NMnt+BE), modified montmorillonite (MMnt) and modified montmorillonite with added blueberry extract (MMnt+BE).

\subsection{Characterization of clays}

\subsubsection{X-ray diffraction (XRD)}

The X-ray diffraction patterns of the clay powders were 
determined using an X-Pert Pro diffractometer (Netherlands) operating at $40 \mathrm{kV}$ and $40 \mathrm{~m} \AA$, with $\mathrm{Cu} \mathrm{K}_{\alpha}$ radiation $(\lambda=1.5406 \AA)$. Samples of finely ground clay powder were placed in horizontal glass holders. Diffractograms were recorded at a scanning speed of $0.5^{\circ}$ per min in an angular range of $2 \theta=2^{\circ}-8^{\circ}$. The distances between the planes of the crystals $d(\AA)$ were calculated from the diffraction angles $\left(^{\circ}\right)$ measured from the X-ray patterns, according to Bragg's law:

$d=\frac{n \lambda}{2 \sin \theta}$

where $\lambda$ is the wavelength of radiation $\mathrm{Cu} \mathrm{K}_{\alpha}$ and $n$ is the order of reflection. For the calculations, $n$ was taken as 1 . The differences between the interplanar distances $\left(\Delta_{\mathrm{ip}}\right)$ of the samples tested were calculated taking as a reference the interplanar distance of the natural montmorillonite $\left(d_{\mathrm{NM}}\right)$.

$\Delta_{i d}=d_{c}-d_{N M}$

where $d_{c}$ is the interplanar distance of each clay sample.

\subsubsection{Thermogravimetric analysis (TGA)}

Thermogravimetric analysis was carried out with a thermal analyzer (TA Instruments) Model TGA Q500 (Hüllhorst, Germany) at a heating rate of $10{ }^{\circ} \mathrm{C} / \mathrm{min}$ from room temperature to $900{ }^{\circ} \mathrm{C}$ under nitrogen atmosphere. The clay mass was in the range of $7-15 \mathrm{mg}$. The mole fraction of blueberry extract $\left(\mathrm{X}_{\mathrm{be}}\right)$ incorporated into the clays was calculated as follows:

$X_{b e}=\frac{R w_{n+b e}-R w_{n}}{R w_{b e}-R w_{n}}$

where $R w_{n+b e}$ is residual mass of clay plus blueberry extract, $R w_{n}$ is the residual mass of clay without blueberry extract, and $R w_{\text {be }}$ is the residual mass of blueberry extract. Residual mass values were taken at $800{ }^{\circ} \mathrm{C}$ where the decomposition of the blueberry extract was about $0.7 \%$. Analyses were performed in triplicate to ensure repeatability and data were reported as mean values \pm SD.

\subsubsection{Field emission scanning electron microscopy (FESEM)}

FESEM micrographs of the clays were taken, and their average size calculated using a FESEM Supra55, Zeiss (Oberkochen, Germany) at an acceleration voltage of $3 \mathrm{kV}$. The average size of the clay particles was determined using the well-known image processing software Image by randomly choosing at least 5 FESEM images. All samples were sputter coated with an $\mathrm{Ar}^{+}$ion beam at an energy level of $3 \mathrm{kV}$ and sputter rate $0.67 \mathrm{~nm} / \mathrm{min}$ with a thin layer of gold for $35 \mathrm{~s}$ to ensure electrical conduction and to reduce surface charging during the analysis. The sputter rate was determined using a $\mathrm{Ni} / \mathrm{Cr}$ multilayer standard.

\subsubsection{Moisture content}

The moisture contents of the different clays were determined using a Moisture Analyzer, Model MA150 (Goettingen, Germany). Samples ( $0.5 \mathrm{~g})$ were dried at $105{ }^{\circ} \mathrm{C}$ until constant mass was reached. Measurements were conducted in triplicate for each clay and the results were reported as \% of average moisture \pm SD.

\subsubsection{Water activity $\left(a_{w}\right)$}

The water activity of the different clays was determined in order to evaluate their susceptibility to microbiological growth: a limiting factor for their use as a food additive. Water activity was calculated using a psychrometric $a_{w}$ meter Aqualab Cx-2 (Decagon Devices, Pullman, USA) previously calibrated with water at $25{ }^{\circ} \mathrm{C}$. The average value of three measurements per clay type \pm SD was reported.

\subsubsection{Attenuated total reflectance Fourier transform infrared spectroscopy (ATR/FTIR)}

The infrared spectra of the clay samples were recorded on a Nicolet 8700 (Thermo Scientific Instrument Co., Madison, Wisconsin, USA) equipped with a diamond ATR probe at an incident angle of $45^{\circ}$, over the range $4000-600 \mathrm{~cm}^{-1}$, from 32 co-added scans at $4 \mathrm{~cm}^{-1}$ resolution. About $10 \mathrm{mg}$ of each of the finely ground clay samples were placed on the sample holder. Each sample was scanned three times, observing good reproducibility.

\subsubsection{Raman spectroscopy}

Raman spectra of the clays were obtained using an Invia Reflex confocal Raman microscope (Renishaw, U.K.) with an argon laser. The laser power level was set at $3 \mathrm{~mW}$ and the Raman spectra were acquired at $785 \mathrm{~nm}$. The microscope was operated with a $50 \times$ objective lens to focus the beam onto the sample. Integration time was $0.5 \mathrm{~s}$, and the number of accumulations 200. Spectral resolution and repeatability were better than $1 \mathrm{~cm}^{-1}$ and $0.2 \mathrm{~cm}^{-1}$, respectively. The Raman spectrum for each sample was measured as an evenly-distributed number of points. No thermal effects were observed on the samples during these measurements.

\subsubsection{Color}

The color parameters of the clays were determined with a Macbeth ${ }^{\circledR}$ colorimeter (Color-Eye 2445 model, illuminant D65 and $10^{\circ}$ observer) standardized with a white reference plate $\left(L^{*}=93.52\right.$, $a^{*}=-0.81$ and $\left.b^{*}=1.58\right)$. Hunter scale values were expressed as $L^{*}=0$ (black) to $L^{*}=100$ (white), $-a^{*}$ (greenness) to $+a^{*}$ (redness), $-b^{*}$ (blueness) to $+b^{*}$ (yellowness) [40]. Differences in color $\left(\Delta E^{*}\right)$ were calculated according to Eq. (4) described by Gennadios et al. [41]:

$\Delta E=\sqrt{\Delta a^{2}+\Delta b^{2}+\Delta L^{2}}$

where $\Delta L, \Delta a$ and $\Delta b$ represent variations between the color parameters of the samples and the white standard.

The yellowness index (YI), which as its name suggests determines the degree of yellowness of a substance, was calculated according to ASTM D-1925 [42] and MacFarlane et al. [43] using the CIE $L^{*} a^{*} b^{*}$ scale:

$Y I=\frac{100(1277 X-1067 Z)}{Y}$

Chromaticity $\left(C^{*}\right)$ and hue angle $\left({ }^{\circ} h\right)$ were calculated using the following equations [44]:

$C^{*}=\sqrt[2]{\left(a^{*}\right)^{2}+\left(b^{*}\right)^{2}}$

and

$$
\begin{aligned}
& h(0)=180+\tan ^{-1}\left(b^{*} / a^{*}\right) ; \text { for } a^{*}>0 \text { and } b^{*}<0 \text {, and } \\
& \text { for } a^{*}<0 \text { and } b^{*}>0
\end{aligned}
$$

Measurements were taken in triplicate for each type of clay.

\subsubsection{Response to $\mathrm{pH}$ changes}

In order to evaluate the responses of the clays to changes in $\mathrm{pH}$, samples of each system ( $0.1 \mathrm{~g}$ of clay) were placed in $4 \mathrm{~mL}$ solutions of $\mathrm{pH}$ equal to 1,7 , and 13 , prepared from $\mathrm{NaOH}(0.1 \mathrm{M})$ and $\mathrm{HCl}$ $(0.1 \mathrm{M})$. Changes in clay color were then assessed from images 
taken with an 8.1 mega pixel Cyber-shot Sony camera; model DSCH3 (Tokyo, Japan).

\subsubsection{DPPH antioxidant activity}

The total antioxidant activity of each clay type was determined using the 2,2-diphenyl-2-picrylhydrazyl (DPPH) radical method described by Molyneux [45]. Briefly, $1.97 \mathrm{mg}$ of DPPH radical was dissolved in $50 \mathrm{~mL}$ of pure methanol and adjusted to 1.0 absorbance units at $517 \mathrm{~nm}$. Then, $60 \mu \mathrm{L}$ of each clay sample $(0.01 \mathrm{mg} / \mathrm{mL})$ and $840 \mu \mathrm{L}$ of DPPH radical adjusted solution were mixed in individual tubes and incubated for $60 \mathrm{~min}$ at room temperature in the dark. The absorbance of samples was read at $517 \mathrm{~nm}$ using a UV-visible spectrometer UV-1601 PC (Shimadzu Corporation, Kioto, Japan). The antioxidant activity of the samples tested was expressed as percent inhibition of $\mathrm{DPPH}$, calculated according to the following equation:

\%Inhibition $=\left\lfloor A_{0}-A_{60} / A_{0}\right\rfloor \times 100$

where $A_{0}$ and $A_{60}$ are the absorbance values of the blank sample and the radical plus sample, respectively. Assays were carried out in triplicate.

\subsubsection{Antimicrobial activity of clays - disc-diffusion assay}

The antimicrobial activity of the clays was evaluated by the agar diffusion method according to Ponce et al. [46]. The zone of inhibition on solid media assay was used for determining the antimicrobial effects of the clays against two typical pathogens: a Gramnegative bacteria, Escherichia coli 0157:H7 (32158, American Type Culture Collection), and a Gram-positive bacteria, Listeria monocytogenes innocua, provided by CERELA (Centro de Referencia de Lactobacilos, Tucumán, Argentina). For this, $30 \mu \mathrm{L}$ of each clay were hydrated with $1 \mathrm{~mL}$ of sterile water. The resulting solutions were then poured into $5 \mathrm{~mm}$ diameter wells on Mueller Hinton (Merck, Darmstadt, Germany) agar plates, previously seeded with $0.1 \mathrm{~mL}$ of inoculum containing approximately $10^{5}-10^{6} \mathrm{CFU} / \mathrm{mL}$ of the test bacteria. Plates were incubated for $24 \mathrm{~h}$ at $37^{\circ} \mathrm{C}$, and then examined to study the inhibitory effect. The total area was used to evaluate the antimicrobial potential of the clays by exactly measuring the diameter of the inhibitory zones surrounding the wells, as well as the area in contact with the agar surface. The antimicrobial effect was then classified using the diameter of each inhibition halo as: not sensitive for diameters less than $8 \mathrm{~mm}$; sensitive for diameters of $9-14 \mathrm{~mm}$; very sensitive for diameters of $15-19 \mathrm{~mm}$ and extremely sensitive for diameters larger than $20 \mathrm{~mm}$ [46]. Each assay was performed in triplicate on two separate experimental runs.

\subsection{Statistical analysis}

OriginPro 8 (Version 8.5 , Northampton, USA) was used to analyze the resulting data of the properties of the clays. Data were initially evaluated by analysis of variance (ANOVA) and significant results further analyzed using Duncan's multiple range tests $(p<0.05)$ to compare mean values.

\section{Results and discussion}

\subsection{X-ray diffraction (XRD)}

The X-ray diffraction patterns of the developed clays (Fig. 1) showed that the NMnt exhibited a strong reflection at $2 \theta=4.78^{\circ}$ corresponding to a basal spacing of $18.6 \AA$. Similar results have been reported by Merino et al. [47] for natural bentonite clay (13.2 $\AA$ ). The interlayer spacing of the MMnt (modified) clay ( $d$-value $\cong$ 26.6 A) was significantly wider than that of the NMnt, representing an increase of around $8.0 \AA$ (Table 1). This is consistent with results reported by de Azeredo [5] where inorganic cations in the clays tested were replaced by other organics by means of exchange reactions.

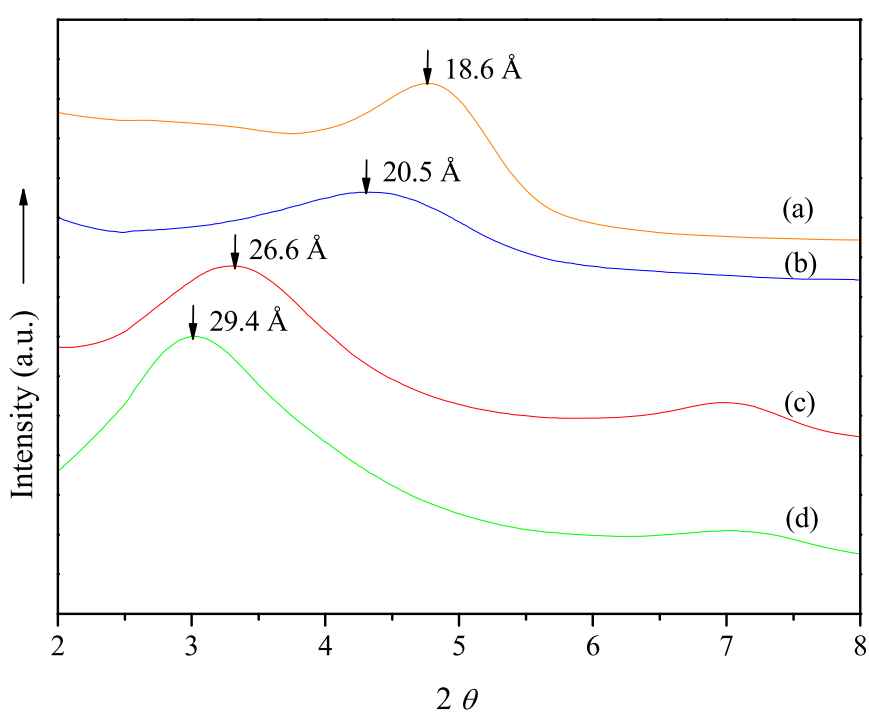

Fig. 1. X-ray diffraction pattern of the different clays studied: (a) natural montmorillonite (NMnt), (b) natural montmorillonite containing blueberry extract (NMnt+BE) (c) modified montmorillonite (MMnt) and (d) modified montmorillonite containing blueberry extract $(\mathrm{MMnt}+\mathrm{BE})$.

Table 1

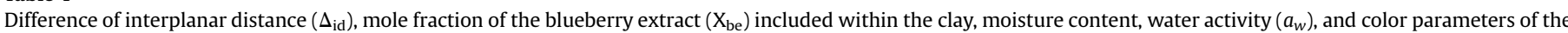
different clays.

\begin{tabular}{|c|c|c|c|c|}
\hline Parameter & NMnt & $\mathrm{NMnt}+\mathrm{BE}$ & MMnt & MMnt + BE \\
\hline$\Delta_{\text {id }}(\AA)$ & - & $1.9 \pm 0.1^{\mathrm{a}}$ & $8.0 \pm 0.1^{b}$ & $10.8 \pm 0.1^{c}$ \\
\hline $\mathrm{X}_{\mathrm{be}}$ & - & $0.21 \pm 0.01^{\mathrm{a}}$ & - & $0.43 \pm 0.01^{\mathrm{b}}$ \\
\hline Moisture (\%) & $1.9 \pm 0.1^{\mathrm{a}}$ & $2.2 \pm 0.1^{\mathrm{b}, \mathrm{a}}$ & $2.1 \pm 0.1^{\mathrm{a}}$ & $2.5 \pm 0.1^{c}$ \\
\hline$a_{w}$ & $0.314 \pm 0.006^{a}$ & $0.526 \pm 0.004^{c}$ & $0.347 \pm 0.009^{b}$ & $0.571 \pm 0.004^{\mathrm{d}}$ \\
\hline$L^{*}$ & $93.13 \pm 0.01^{\mathrm{d}}$ & $53.21 \pm 0.01^{\mathrm{b}}$ & $91.19 \pm 0.01^{c}$ & $40.54 \pm 0.01^{\mathrm{a}}$ \\
\hline$a^{*}$ & $-0.73 \pm 0.01^{\mathrm{a}}$ & $0.70 \pm 0.02^{c}$ & $-0.51 \pm 0.01^{\mathrm{b}}$ & $4.80 \pm 0.02^{\mathrm{d}}$ \\
\hline$b^{*}$ & $11.52 \pm 0.01^{\mathrm{c}}$ & $-2.58 \pm 0.03^{b}$ & $13.24 \pm 0.06^{\mathrm{d}}$ & $-9.95 \pm 0.01^{\mathrm{a}}$ \\
\hline Color difference $(\Delta E)$ & $9.95 \pm 0.01^{\mathrm{a}}$ & $40.57 \pm 0.01^{\mathrm{c}}$ & $11.90 \pm 0.01^{\mathrm{b}}$ & $54.53 \pm 0.01^{\mathrm{d}}$ \\
\hline Whiteness Index (WI) & $86.57 \pm 0.01^{\mathrm{d}}$ & $53.13 \pm 0.01^{\mathrm{b}}$ & $84.09 \pm 0.01^{c}$ & $39.52 \pm 0.01^{\mathrm{a}}$ \\
\hline Yellow Index $(Y I)$ & $20.74 \pm 0.02^{c}$ & $-7.30 \pm 0.06^{\mathrm{b}}$ & $24.27 \pm 0.01^{\mathrm{d}}$ & $-34.33 \pm 0.07^{\mathrm{a}}$ \\
\hline$C^{*}$ & $11.54 \pm 0.01^{\mathrm{c}}$ & $2.68 \pm 0.03^{\mathrm{a}}$ & $13.2497 \pm 0.0002^{\mathrm{d}}$ & $11.049 \pm 0.005^{\mathrm{b}}$ \\
\hline$h\left({ }^{\circ}\right)$ & $176.36 \pm 0.03^{a}$ & $344.8 \pm 0.3^{\mathrm{d}}$ & $177.81 \pm 0.02^{\mathrm{b}}$ & $334.2 \pm 0.1^{\mathrm{c}}$ \\
\hline
\end{tabular}

Equal letters in the same row indicate no statistically significant differences ( $\mathrm{p} \leq 0.05$ ). 


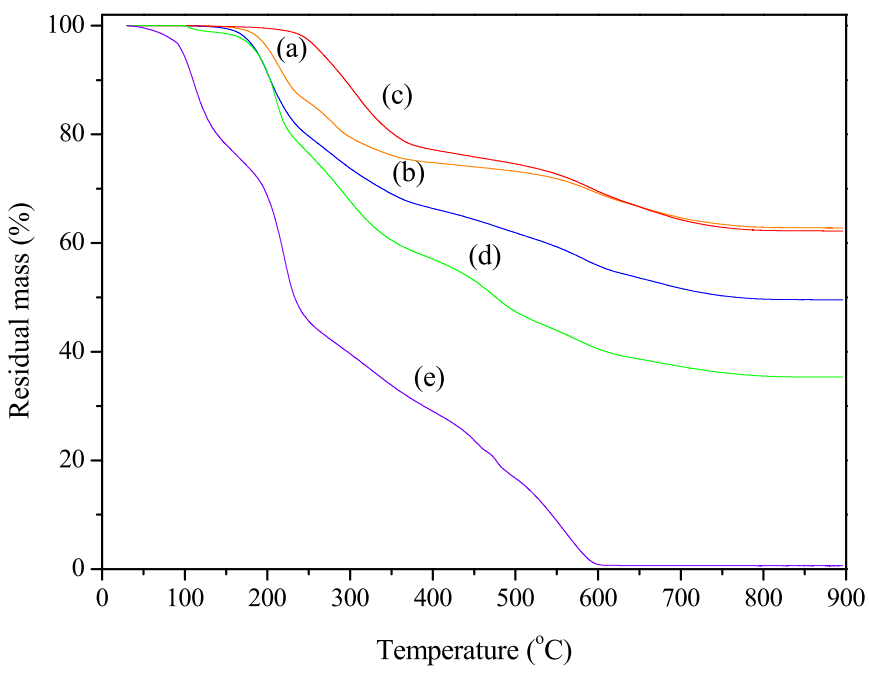

Fig. 2. TGA curves of the different systems studied: (a) natural montmorillonite (NMnt), (b) natural montmorillonite containing blueberry extract (NMnt+BE), (c) modified montmorillonite (MMnt), (d) modified montmorillonite containing blueberry extract $(\mathrm{MMnt}+\mathrm{BE})$ and (e) blueberry extract $(\mathrm{BE})$.

The 001 basal reflection of both the NMnt and MMnt was increased by adding the blueberry extract, demonstrated by the decrease in the $2 \theta$ angles in the extract-containing clays (NMnt+BE and MMnt+BE) (Fig. 1). This suggests that the increase in basal spacing was a result of the intercalation of blueberry extract molecules in the silicate interlayer spaces of the clays [48] confirming that the extract was nano-packaged in the clays. In other words, the blueberry extract was introduced into the Mnt interlayer space.

\subsection{Thermogravimetric analysis (TGA)}

The curves obtained from TGA analysis (Fig. 2) were used to examine changes in the thermal stability of the systems evaluated and to calculate the mole fraction of blueberry extract $\left(\mathrm{X}_{\mathrm{be}}\right)$ incorporated into the clays. Thermal decomposition of the clays occurred in three steps: step one from room temperature up to approximately $150{ }^{\circ} \mathrm{C}$, corresponding to the loss of physically adsorbed water molecules; step two between 150 and $450{ }^{\circ} \mathrm{C}$, where slow water loss occurs from between the interlayers; step three from $650{ }^{\circ} \mathrm{C}$, corresponding to the dehydroxylation of the structural $\mathrm{OH}$ groups of the clays $[49,50]$.

Firstly, we can observe that the removal of physically adsorbed water molecules in the blueberry extract-containing clays (NMnt+BE and MMnt+BE) was shifted to lower temperatures compared to the NMnt clay, i.e. between room temperature and $120{ }^{\circ} \mathrm{C}[51,52]$. This suggests that water molecules interact weakly with these clays, possibly because the polar sites (Lewis sites) available are found blocked by blueberry extract molecules.

The maximum decomposition temperature of the modified clay (MMnt) was higher than that of the other clays (Fig. 2). This agrees with reports in the literature which indicate that the organoammonium groups grafted to the silicates show high thermal stability and start to decompose only at $400{ }^{\circ} \mathrm{C}$ [49]. In contrast, the native and modified clays with added blueberry extract (NMnt $+\mathrm{BE}$ and MMnt $+\mathrm{BE}$, respectively) had a lower heat resistance, possibly due to the decomposition of the interleaved organic matter contained in the interlayer spaces of the clay. Interestingly, the $\mathrm{MMnt}+\mathrm{BE}$ clay also showed a greater mass loss, suggesting a higher content of packed organic material within the interlayer spaces of the modified Mnt. In this regard, the highest $X_{\text {be }}(\sim 0.43)$ incorporated into the clays was obtained for the MMnt+BE clay as calculated from the TGA curves (Table 1). This high organic matter content can be explained by the fact that the modified Mnt had the widest interlayer spacing [53], thus making more room available for the packaged blueberry extract.

\subsection{Field emission scanning electron microscopy (FESEM)}

The FESEM micrographs of the clays (Fig. 3) revealed that the clay particles were slightly transformed from an irregular (NMnt clay; Fig. 3a) to a spherical morphology (MMnt clay; Fig. 3c), although the irregular clay remained predominant. The average size of the nanoclay particles also increased from approximately 20 - $37 \mu \mathrm{m}$ (NMnt clay) to 40-57 $\mu \mathrm{m}$ (MMnt clay). These results agree with the increase in the interlayer spacing observed from the XRD patterns. Similar results have been reported by Öztop, \& Shahwan [54] for Mnt modified using an alkaline hydrothermal treatment.

An increase in the average size of the clay particles was also observed for the clays nano-packaged with blueberry extract. This is again in line with the XRD results. According to Ruiz et al. [55], one of the factors affecting the morphology of this type of material is that it undergoes a zeolitization process characteristic of the medium, in which ions, such as $\mathrm{Na}^{+}$and $\mathrm{K}^{+}$, act as templates around the aluminosilicate units.

\subsection{Moisture content}

The moisture content data for the different clays studied (Table 1) reveals that the moisture contents of the NMnt and MMnt clays were not statistically significant ( $p \geq 0.05$ ). The addition of blueberry extract did, however, significantly increase $(p \leq 0.05)$ clay moisture content (NMnt $+\mathrm{BE}$ and $\mathrm{MMnt}+\mathrm{BE})$. This suggests that the incorporation of blueberry extract increases the susceptibility of clays to the adsorption of water from the environment. The MMnt+BE clay was the wettest system, possibly because of the higher $\mathrm{X}_{\mathrm{be}}$ that was incorporated into this clay.

\subsection{Water activity $\left(a_{w}\right)$}

The water activity $\left(a_{w}\right)$ values of the clays used (Table 1 ) shows a direct relationship between $a_{w}$ and moisture content. The highest $a_{w}$ value ( 0.571) was obtained for samples of blueberry extractcontaining modified Mnt (MMnt+BE) which contained the highest mole fraction of the blueberry extract within the clay. Water activity values between 0.6 and 0.8 allow the growth of molds and yeasts, whereas for values between 0.8 and 1.0 bacterial growth is more likely. The $a_{w}$ values obtained here thus suggest that the developed clays are not susceptible to microbiological growth [56].

\subsection{Attenuated total reflectance Fourier transform infrared spectroscopy (ATR/FTIR)}

The FTIR spectra for the developed clays over the entire absorption range (Fig. 4A) show absorption peaks at about $3334 \mathrm{~cm}^{-1}$, corresponding to the stretching and bending vibrations for the hydroxyl $(\mathrm{O}-\mathrm{H})$ groups of the water molecules present in the clay samples [47,57]. The increase in intensity of the peak at $3334 \mathrm{~cm}^{-1}$ due to $\mathrm{O}-\mathrm{H}$ stretching vibrations suggests that the available cations are replaced by protons of polar groups during the different treatments, thus increasing the number of available $\mathrm{O}-\mathrm{H}$ groups [57]. Specifically, in the region between 3600 and $3000 \mathrm{~cm}^{-1}$ the intensity of the absorption band associated with the $\mathrm{O}-\mathrm{H}$ groups and free water increases, which can be directly related to the moisture content of the clays (Table 1). In other words, higher moisture contents led to stronger absorption band associated with the $\mathrm{O}-\mathrm{H}$ 

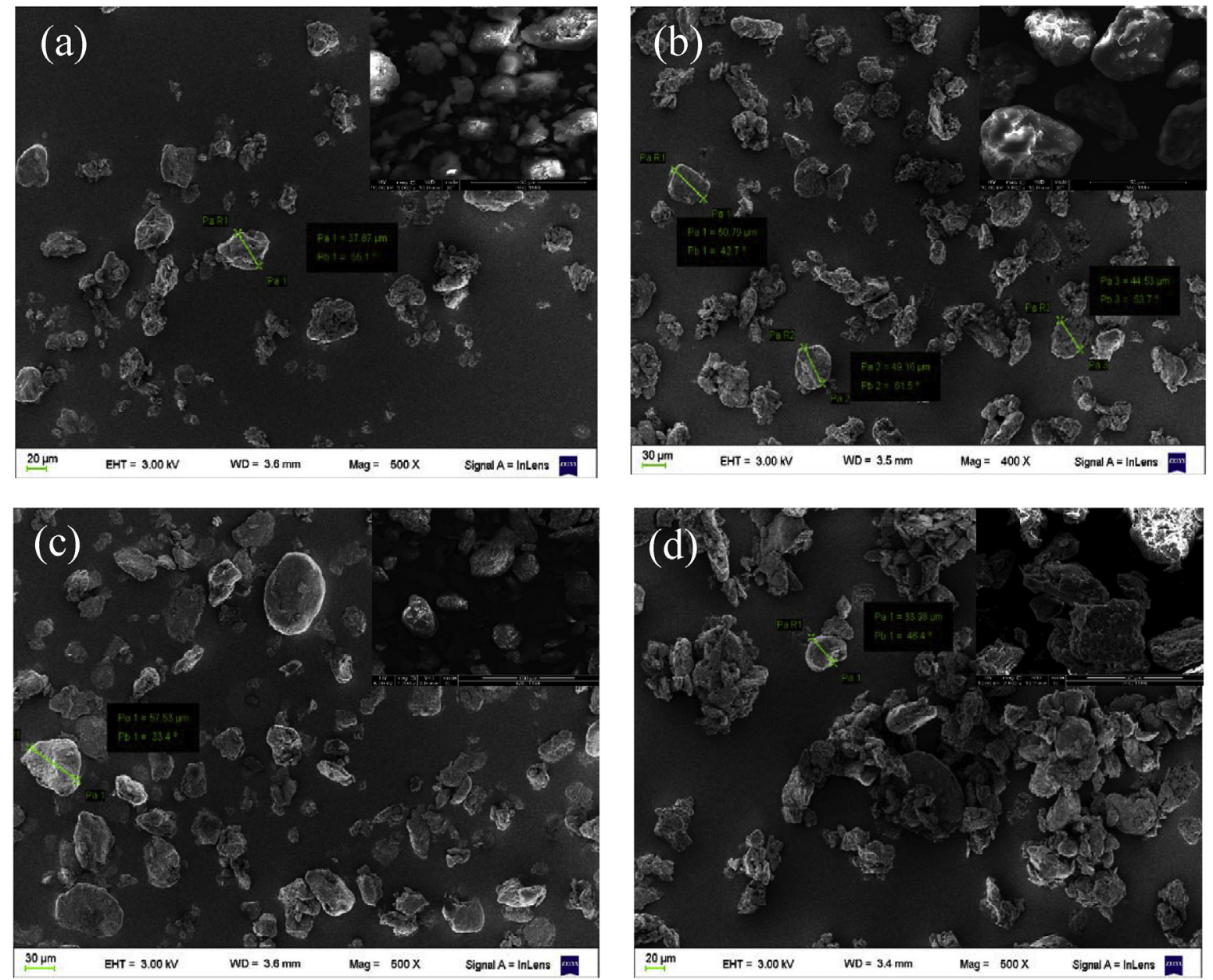

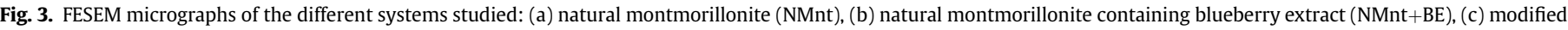
montmorillonite (MMnt) and (d) modified montmorillonite containing blueberry extract (MMnt+BE).

groups and free water. The bands located at $2918 \mathrm{~cm}^{-1}, 2850 \mathrm{~cm}^{-1}$, $2361 \mathrm{~cm}^{-1}$ and $1469 \mathrm{~cm}^{-1}$ correspond to the $\mathrm{CO}_{2}$ environment. The absorption band centered at around $999 \mathrm{~cm}^{-1}$ is attributed to the $\mathrm{Si}-\mathrm{O}$ group in plane vibration. $\mathrm{Al}-\mathrm{Al}-\mathrm{OH}, \mathrm{Al}-\mathrm{Fe}-\mathrm{OH}$ and $\mathrm{Al}-\mathrm{M}-$ $\mathrm{g}-\mathrm{OH}$ bending vibrations show absorption bands at 916, 880 and $800 \mathrm{~cm}^{-1}$, respectively [58-60]. A diminution in the intensity of the bands at $999 \mathrm{~cm}^{-1}\left(\mathrm{Si}-\mathrm{O}\right.$ stretching) and $814 \mathrm{~cm}^{-1}(\mathrm{O}-\mathrm{Si}-\mathrm{O}$ asymmetric stretching) due to changes in the Si environment can also be observed.

The FTIR spectrum for the blueberry extract (mainly anthocyanins) also shows an absorption peak at about $3334 \mathrm{~cm}^{-1}$ (Fig. 4B) assigned to the stretching and bending vibrations of the $\mathrm{O}-\mathrm{H}$ groups. In addition, a strong absorption band with a maximum at $1021 \mathrm{~cm}^{-1}$ assigned to aromatic ring $\mathrm{C}-\mathrm{H}$ deformation, as well as bands at 1638 and $1414 \mathrm{~cm}^{-1}$ corresponding to the stretching vibration of the $\mathrm{C}-\mathrm{C}$ aromatic ring, can also be seen. The absorption band with a maximum at $1257 \mathrm{~cm}^{-1}$ is assigned to the stretching of pyran rings, typical of flavonoid compounds. Finally, the band appearing at $1344 \mathrm{~cm}^{-1}$ corresponds to $\mathrm{C}-\mathrm{O}$ angular deformations of phenols [31].

\subsection{Raman spectroscopy}

Raman spectroscopy was used in an attempt to investigate the structure of the developed nano-clays a little further. Fig. 5 shows the Raman spectra of the clay samples obtained. This technique is more sensitive in the short range order than XRD, as different crystal modifications of Mnt produce different sets of characteristic Raman bands [61]. Obvious differences in the Raman spectra of the NMnt and MMnt samples were observed, confirming the modification of the clay. However, the samples containing blueberry extract (NMnt $+\mathrm{BE}$ and MMnt $+\mathrm{BE}$ ) did not show clear bands. This suggests that blueberry extract produces a fluorescence phenomenon in clay samples, thus limiting the detection of the spectra [61-66].

\subsection{Color}

The results of the color parameters of the clays studied (Table 1) show that the highest $L^{*}$ value was obtained for the NMnt clay, followed by the MMnt, NMnt $+\mathrm{BE}$ and MMnt $+\mathrm{BE}$ clays, in that order. This indicates that both clay modification and the addition of blueberry extract led to darker clays. The MMnt+BE clay was the darkest of the four types, possibly due to the greater molar fraction of blueberry extract packaged in this system.

The incorporation of the blueberry extract in the clays also increased the $a^{*}$ (redness) values probably due to the blueberry extract pigment (anthocyanins). The reddest clay was the MMnt+BE clay, which would be in line with that established above, i.e. the MMnt+BE clay was the system with the greatest capacity to package the blueberry extract. In contrast, the clays without blueberry extract tended towards a green color, with the most negative 
(A)

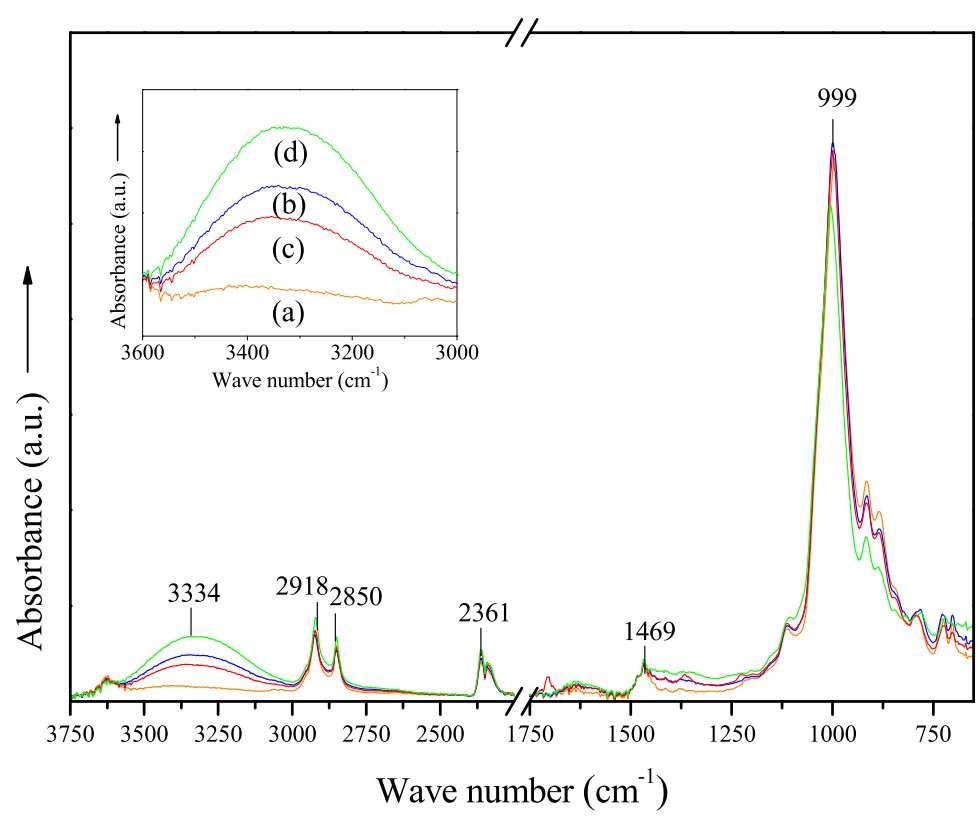

(B)

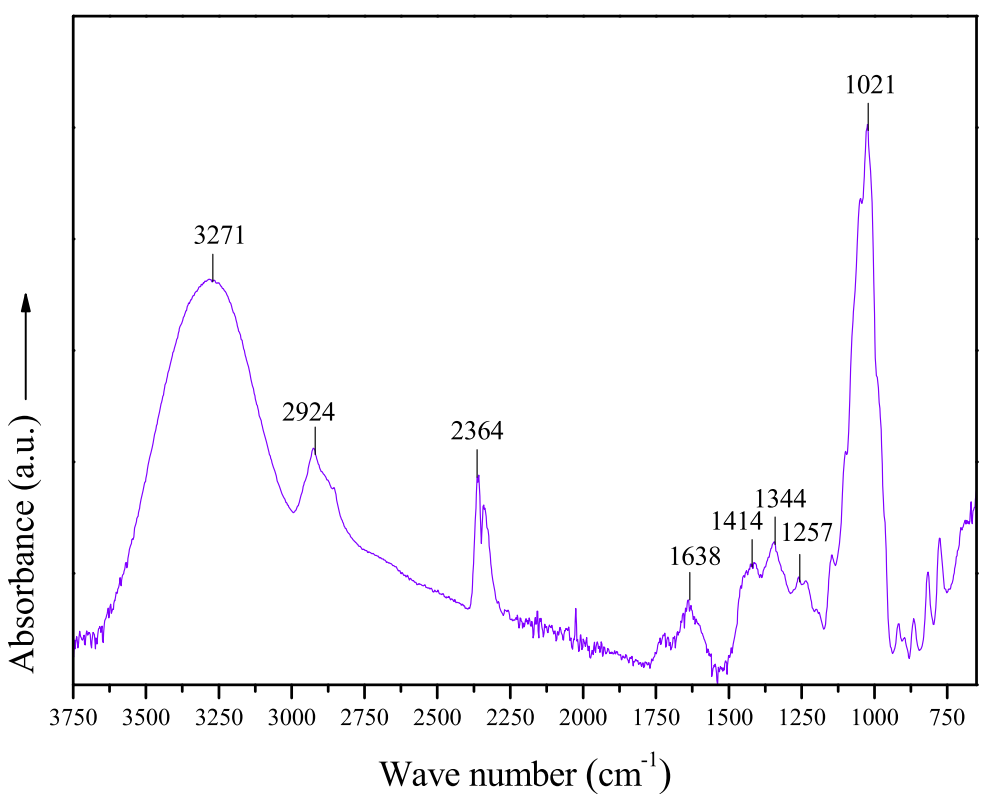

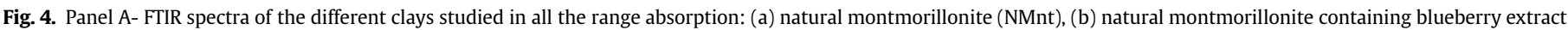

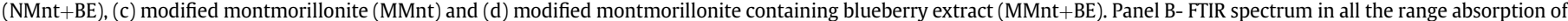
the blueberry extract.

$a^{*}$ value registered for the NMnt clay, i.e. NMnt is the system with the greatest tendency towards green.

The MMnt clay showed the highest positive $b^{*}$ value, showing that this was the most yellow system. Unsurprisingly, a direct relationship between the $b^{*}$ values and yellowness index $(Y I)$ was obtained.

The combination of all the changes observed in each of the $L^{*}, a^{*}$ and $b^{*}$ chromatographic parameters produced lower color differences $(\Delta E)$ between the clays without blueberry extract. This is consistent with the $W I$ indexes obtained, since the $\Delta E$ values were calculated taking a standard white plate as a reference. According to Obón et al. [67], $\Delta E$ 's from 0 to 1.5 can be considered small and virtually identical to the human eye, from 1.5 to 5 color differences can be distinguished, and are obvious for $\Delta E$ 's higher than 5 . The color differences between the clay samples and the standard white reference plate was thus evident as detected by visual observation. Similarly, the clay samples with added blueberry extract (NMnt+BE and MMnt $+\mathrm{BE}$ ) were clearly different in color to the samples without the extract (NMnt and MMnt).

A decrease in the chromaticity $\left(C^{*}\right)$ values was also observed when the blueberry extract was incorporated into the clay systems. The NMnt+BE clay showed the lowest chromaticity value, meaning that clay had a less vivid color.

The hue angles $\left({ }^{\circ} h\right)$ of the clay systems were correctly located in the quadrants of the CIE $L^{*} a^{*} b^{*}$ color chart. 


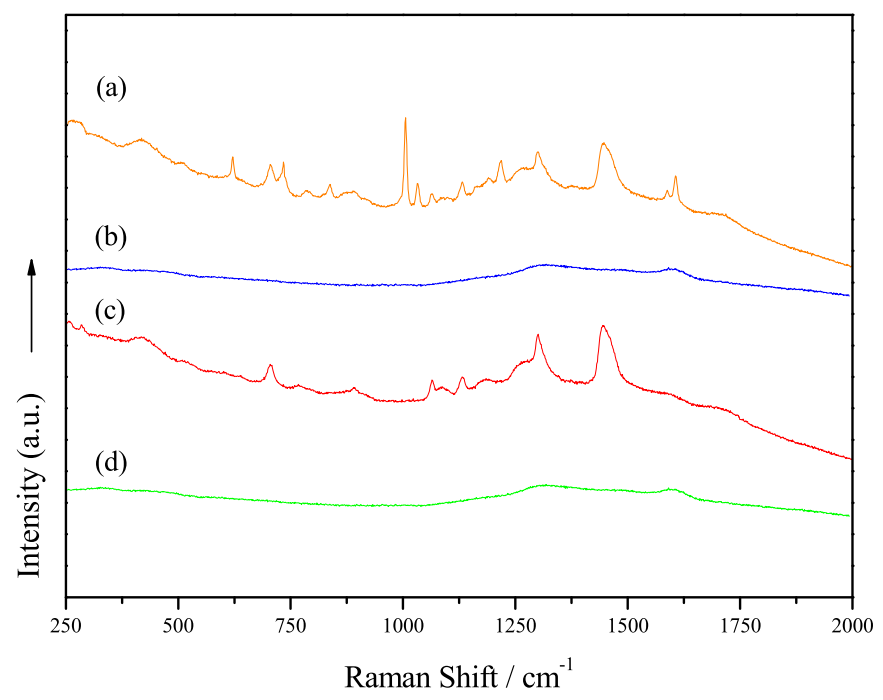

Fig. 5. Raman spectra of the different systems studied: (a) natural montmorillonite (NMnt), (b) natural montmorillonite containing blueberry extract (NMnt+BE), (c) modified montmorillonite (MMnt) and (d) modified montmorillonite containing blueberry extract (MMnt+BE).

\subsection{Response to $\mathrm{pH}$ changes}

The images of the responses of the clays to different pH (Fig. 6) reveal that the clays with added blueberry extract (NMnt+BE and MMnt $+\mathrm{BE}$ ) changed color in both the acid and alkaline mediums. Both these clays showed a red coloration at the acid $\mathrm{pH}$ due to the formation of the flavylium cation (red color) of anthocyanins contained in the blueberry extract. In contrast, at alkaline $\mathrm{pH}$ the clays with blueberry extract (NMnt+BE and MMnt $+\mathrm{BE}$ ) changed to a green color as a result of the quinoidal structure of anthocyanins that forms at $\mathrm{pH}>8$ [68]. At $\mathrm{pH}=7$ the blueberry extractcontaining clays had a purple coloration.

These results suggest that incorporating blueberry extract into nanoclays imparts them with intelligent behavior as it enables them to respond to $\mathrm{pH}$ changes in the surrounding environment. These intelligent nanocomposites could be applied in polymeric matrices in contact with fishery products since the production and accumulation of amines, mainly ammonia, trimethylamine, and histamine, as a result of microbial growth would produce an alkaline medium. This would cause blueberry extract-containing clays to change in color, indicating a loss of quality in these types of foods. Similarly, these nanocomposites could be applied in slightly acidic food polymeric matrices, such as meats and fruits [31].

Interestingly, not only the color of the blueberry extractcontaining clays changed, but also, slightly, the solution they were in. This confirms the migration of anthocyanin molecules toward the aqueous medium. Anthocyanins can then act as tracers of events occurring within the clay. This suggests that the anthocyanins packaged within the interlayer spaces of the clays generate van der Waals-type interactions between clay and pigment. Otherwise the chromophore groups of the anthocyanins would not allow color changes in the clays under different $\mathrm{pH}$ conditions.

\subsection{DPPH antioxidant activity}

The results of antioxidant capacity of the clays developed (Fig. 7) show that the native and modified Mnt (NMnt and MMnt) had an almost negligible antioxidant activity ( 1.5\%).

In contrast, the blueberry extract (BE) demonstrated a potent antioxidant effect (approx. 90\% inhibition of the DPPH radical),
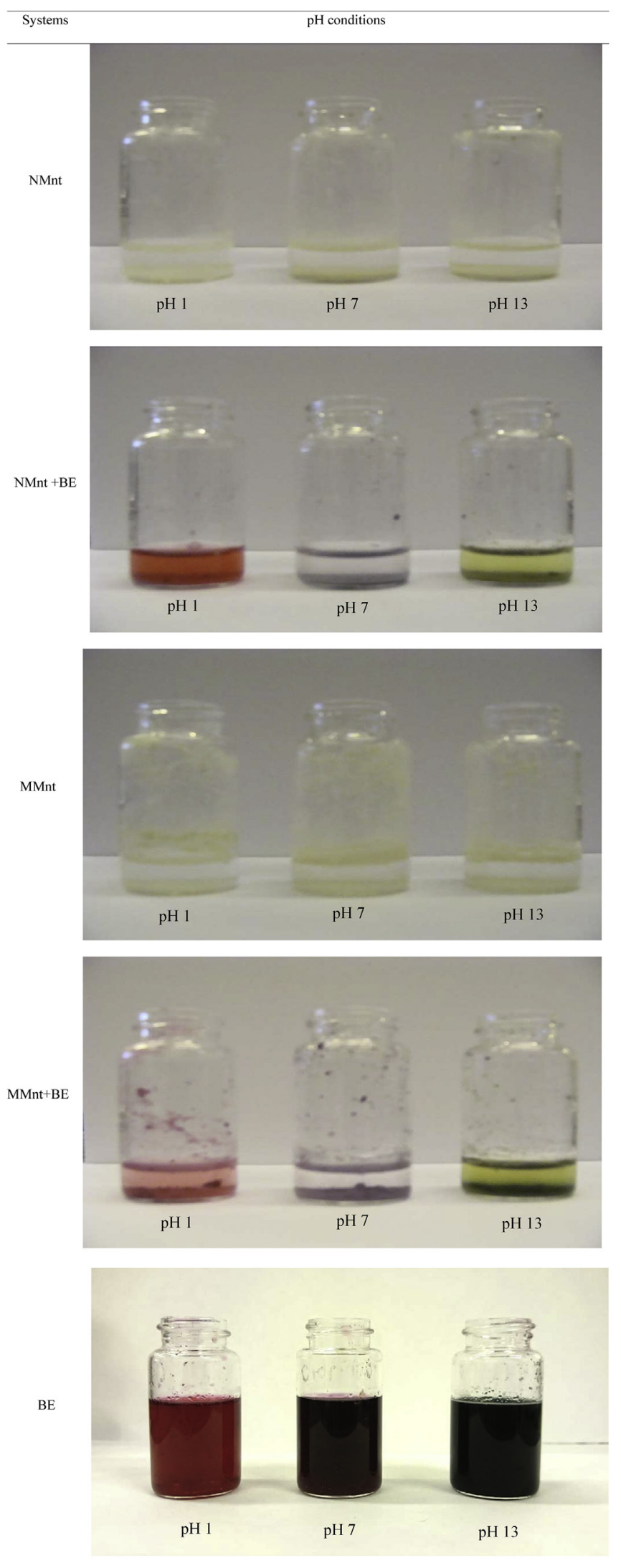

Fig. 6. Response of the systems evaluated at different conditions of $\mathrm{pH}$ : natura montmorillonite (NMnt), natural montmorillonite containing blueberry extract $(\mathrm{NMnt}+\mathrm{BE})$, modified montmorillonite (MMnt), modified montmorillonite containing blueberry extract (MMnt+BE) and blueberry extract (BE). 


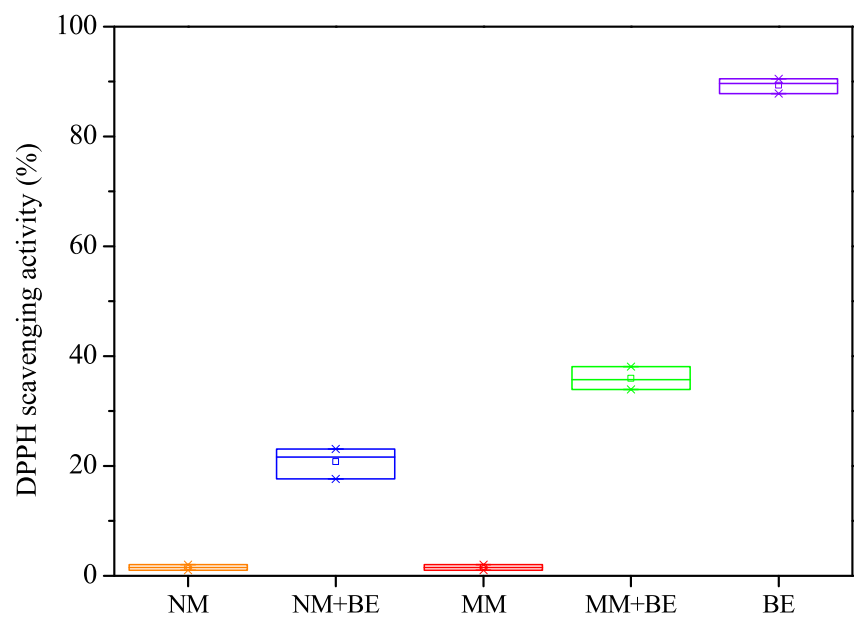

Fig. 7. DPPH scavenging activity of the clays and the extract evaluated: natural montmorillonite (NMnt), natural montmorillonite containing blueberry extract (NMnt+BE), modified montmorillonite (MMnt), modified montmorillonite containing blueberry extract $(\mathrm{MMnt}+\mathrm{BE})$ and blueberry extract $(\mathrm{BE})$.

giving it a potential functional effect. This is consistent with results reported in the literature [34]. A direct link between the mole fraction of blueberry extract $\left(\mathrm{X}_{\mathrm{be}}\right)$ contained within the clays and the antioxidant activity of these systems (NMnt+BE and $\mathrm{MMnt}+\mathrm{BE}$ ) was also found. The antioxidant effect of these clays can, thus, be attributed to the nano-packaged blueberry extract contained within them. The blueberry extract-containing modified clay $(\mathrm{MMnt}+\mathrm{BE})$ showed an antioxidant activity $\sim 1.66$ times greater than that of the NMnt+BE clay. This could be because the former has a larger interlayer spacing allowing for a greater packaging capacity. Modifying the Mnt may also ensure that the antioxidant properties of the blueberry extract are better preserved.

Finally, the measurement of the antioxidant activity in these systems allows us to confirm the migration of the nano-packed compounds from the clays to the aqueous medium.

\subsection{Antimicrobial activity of the clays - disc-diffusion assay}

The antimicrobial capacity of the clays was evaluated in order to establish their potential as active nanocomposites. Neither the clays nor the blueberry extract, however, showed antimicrobial activity against the two pathogenic microorganisms tested (Escherichia coli 0157:H7 and Listeria monocytogenes innocua). Similar results were obtained by de Azeredo [5] and Abreu et al. [69] for unmodified Mnt. Other studies, nevertheless, have reported antimicrobial activity from two commercial modified Mnt clays: Cloisite 20A and Cloisite 30B [5,69]. Finally, although migration of the blueberry extract towards the surrounding environment was demonstrated, it did not show significant antimicrobial activity. Despite this, no microbiological growth was registered on the clays, thus agreeing with the water activity results.

\section{Conclusions}

The nanoclays developed have potential as nano-packaging materials for the development of bio-nanocomposites applicable to the cosmetic, biomedical, and food industries, among others: the antioxidant activity of the blueberry extract was maintained in these systems, and the blueberry extract-containing clays showed intelligent behavior when tested under different $\mathrm{pH}$ conditions. Unfortunately, however, none of the clays showed antimicrobial activity so that the hypothesis of the active effects of the systems obtained had to be discarded. Despite this, the food nanopackaging developed could be used as a potential reinforcement material in thermoplastic composites. Modifying the Mnt increased the interlayer spacing, thus allowing more blueberry extract to be packaged. Finally, the nanoclays obtained show promise as nanocontainers for converting substances initially found in a liquid state into solid-state powders, thereby facilitating their manipulation and transport.

\section{Conflicts of interest}

The authors declares no conflict of interest.

\section{Acknowledgements}

The authors would like to thank the Consejo Nacional de Investigaciones Científicas y Técnicas (CONICET) (Postdoctoral fellowship internal PDTS-Resolution 2417), Universidad Nacional de Mar del Plata (UNMdP), for the financial support and to Dr. Mirian Carmona-Rodríguez.

\section{References}

[1] Park, Nanotechnology and the packaging of food and other fast- moving consumer goods, in: N. Farmer (Ed.), Trends in Packaging of Food, Beverages and Other Fast-moving Consumer Goods (FMCG): Markets, Materials and Technologies, 2013, pp. 241-260, http://dx.doi.org/10.1533/ 9780857098979.241.

[2] J.Y. Huang, X. Li, W. Zhou, Safety assessment of nanocomposite for food packaging application, Trends Food Sci. Tech. 45 (2015) 187-199.

[3] B. Chen, J.R. Evans, Thermoplastic starch-clay nanocomposites and their characteristics, Carbohydr. Polym. 61 (2005) 455-463.

[4] H.M. Wilhelm, M.R. Sierakowski, G.P. Souza, F. Wypych, Starch films reinforced with mineral clay, Carbohydr. Polym. 52 (2003) 101-110.

[5] H.M. de Azeredo, Antimicrobial nanostructures in food packaging, Trends Food Sci. Tech. 30 (2013) 56-69.

[6] J.W. Rhim, Y.T. Kim, Biopolymer-based composite packaging materials with nanoparticles, Innov. Food Packag. (2014) 413-442.

[7] M. Alexandre, P. Dubois, Polymer-layered silicate nanocomposites: preparation, properties and uses of a new class of materials, Mater. Sci. Eng. Rep. 28 (2000) 1-63.

[8] T. Mandalia, F. Bergaya, Organo clay mineral-melted polyolefin nanocomposites effect of surfactant/CEC ratio, J. Phys. Chem. Solids 67 (2006) 836-845.

[9] E. Picard, H. Gauthier, J.-F. Gérard, E. Espuche, Influence of the intercalated cations on the surface energy of montmorillonites: consequences for the morphology and gas barrier properties of polyethylene/montmorillonites nanocomposites, J. Colloid. Interf. Sci. 307 (2007) 364-376.

[10] F. Bergaya, M. Jaber, J.-F. Lambert, Clays and clay minerals, in: M. Galimberti (Ed.), Rubber-clay Nanocomposites: Science, Technology, and Applications, John Wiley \& Sons, Inc, 2011, pp. 1-44.

[11] R. Ollier, A. Vázquez, V. Alvarez, Biodegradable Nanocomposites Based on Modified Bentonite and Polycaprolactone, in: Advances in Nanotechnology, 10, Nova Publishers, NY, USA, 2011. ISBN: 978-1-62100-150-8.

[12] E. Ruiz-Hitzky, A. Van Meerbeek, Clay Mineral-and organoclay-polymer nanocomposite, Dev. Clay Sci. 1 (2006) 583-621.

[13] R. Ollier, E. Rodriguez, V. Alvarez, Unsaturated polyester/bentonite nanocomposites: influence of clay modification on final performance, Compos. Part A Appl. S 48 (2013) 137-143.

[14] F.-H. Lin, Y.-H. Lee, C.-H. Jian, J.-M. Wong, M.-J. Shieh, C.-Y. Wang, A study of purified montmorillonite intercalated with 5-fluorouracil as drug carrier, Biomaterials 23 (2002) 1981-1987.

[15] Y. Dong, S.S. Feng, Poly (d, l-lactide-co-glycolide)/montmorillonite nanoparticles for oral delivery of anticancer drugs, Biomaterials 26 (2005) 6068-6076.

[16] J.P. Zheng, L. Luan, H.Y. Wang, L.F. Xi, K.D. Yao, Study on ibuprofen/montmorillonite intercalation composites as drug release system, Appl. Clay Sci. 36 (2007) 297-301.

[17] J.K. Park, Y.B. Choy, J.M. Oh, J.Y. Kim, S.J. Hwang, J.H. Choy, Controlled release of donepezil intercalated in smectite clays, Int. J. Pharm. 359 (2008) 198-204.

[18] Y.-H. Lee, T.-F. Kuo, B.-Y. Chen, Y.-K. Feng, Y.-R. Wen, W.-C. Lin, F. Lin, Toxicity assessment of montmorillonite as a drug carrier for pharmaceutical applications: yeast and rats model, Biomed. Eng. Appl. Basis C 17 (2005) 72-78.

[19] X. Wang, Y. Du, J. Luo, Biopolymer/montmorillonite nanocomposite: preparation, drug-controlled release property and cytotoxicity, Nanotechnology 19 (2008) 065707

[20] N. Zhou, S. Fang, D. Xu, J. Zhang, H. Mo, J. Shen, Montmorillonite-phosphatidyl choline/PDMS films: a novel antithrombogenic 
material, Appl. Clay Sci. 46 (2009) 401-403.

[21] B. Wicklein, M. Darder, P. Aranda, E. Ruiz-Hitzky, Phospholipid-sepiolite biomimetic interfaces for the immobilization of enzymes, ACS Appl. Mater. Interfaces 3 (2011) 4339-4348.

[22] S. Mallakpour, M. Dinari, Biomodification of cloisite $\mathrm{Na}^{+}$with L-methionine amino acid and preparation of poly (vinyl alcohol)/organoclay nanocomposite films, J. Appl. Polym. Sci. 124 (2012) 4322-4330.

[23] S. Mallakpour, M. Dinari, Preparation, characterization, and thermal properties of organoclay hybrids based on trifunctional natural amino acids, J. Therm. Anal. Calorim. 111 (2013) 611-618.

[24] K. Nagy, G. Bíró, O. Berkesi, D. Benczédi, L. Ouali, I. Dékány, Intercalation of lecithins for preparation of layered nanohybrid materials and adsorption of limonene, Appl. Clay Sci. 72 (2013) 155-162.

[25] D. Songurtekin, E.E. Yalcinkaya, D. Ag, M. Seleci, D.O. Demirkol, S. Timur, Histidine modified montmorillonite: laccase immobilization and application to flow injection analysis of phenols, Appl. Clay Sci. 86 (2013) 64-69.

[26] W.H. Yu, N. Li, D.S. Tong, C.H. Zhou, C.X.C. Lin, C.Y. Xu, Adsorption of proteins and nucleic acids on clay minerals and their interactions: a review, Appl. Clay Sci. 80 (2013) 443-452.

[27] M. Bracone, D. Merino, J.S. Gonzalez, V.A. Alvarez, T.J. Gutiérrez, Chapter 6 Nanopackaging from natural fillers and biopolymers for the development of active and intelligent films, in: Inc, in: S. Ikram, S. Ahmed (Eds.), Natural Polymers: Derivatives, Blends and Composites, vol. I, Nova Science Publishers, New York, USA, 2016.

[28] F.A. Aouada, L.H. Mattoso, E. Longo, Enhanced bulk and superficial hydrophobicities of starch-based bionanocomposites by addition of clay, Ind. Crop. Prod. 50 (2013) 449-455.

[29] K. Gould, K.M. Davies, C. Winefield (Eds.), Anthocyanins: Biosynthesis, Functions, and Applications, Springer Science \& Business Media, 2008.

[30] C.M. Yoshida, V.B.V. Maciel, M.E.D. Mendonça, T.T. Franco, Chitosan biobased and intelligent films: monitoring pH variations, LWT Food Sci. Technol. 55 (2014) 83-89.

[31] V.A. Pereira, I.N.Q. de Arruda, R. Stefani, Active chitosan/PVA films with anthocyanins from Brassica oleraceae (Red Cabbage) as time-temperature indicators for application in intelligent food packaging, Food Hydrocoll. 43 (2015) 180-188.

[32] Pérdidas y desperdicio de alimentos en el mundo-Alcance, causas y prevención, FAO. Food and Agriculture Organization of the United Nations, Roma, Italia, 2012, pp. 1-33. http://www.fao.org/docrep/016/i2697s/i2697s.pdf.

[33] T.J. Gutiérrez, R. Guzmán, C.M. Jaramillo, L. Famá, Effect of beet flour on films made from biological macromolecules: native and modified plantain flour, Int. J. Biol. Macromol. 82 (2016) 395-403.

[34] C.C. Neto, Cranberry and its phytochemicals: a review of in vitro anticancer studies, J. Nutr. 137 (2007) 186S-193S.

[35] R.G. Jepson, J.C. Craig, Cranberries for preventing urinary tract infections, Cochrane Libr. (2008), http://dx.doi.org/10.1002/14651858.CD001321.pub4.

[36] R.S. Boethling, Environmental fate and toxicity in wastewater treatment of quaternary ammonium surfactants, Water Res. 18 (1984) 1061-1076.

[37] I.K. Breakwell, J. Homer, M.A. Lawrence, W.R. McWhinnie, Studies of organophilic clays: the distribution of quaternary ammonium compounds on clay surfaces and the role of impurities, Polyhedron 14 (1995) 2511-2518.

[38] M. Kozak, L. Domka, Adsorption of the quaternary ammonium salts on montmorillonite, J. Phys. Chem. Solids 65 (2004) 441-445.

[39] J. Dai, A. Gupte, L. Gates, R.J. Mumper, A comprehensive study of anthocyanincontaining extracts from selected blackberry cultivars: extraction methods, stability, anticancer properties and mechanisms, Food Chem. Toxicol. 47 (2009) 837-847.

[40] F.J. Francis, F.M. Clydesdale, Food Colorimetry: Theory and Applications, AVI Publishing Co. Inc, 1975.

[41] A. Gennadios, C.L. Weller, M.A. Hanna, G.W. Froning, Mechanical and barrier properties of egg albumen films, J. Food Sci. 61 (1996) 585-589.

[42] ASTM D-1925, Standard Test Method for Yellowness Index of Plastics, American Society for Testing and Materials, Philadelphia, 1995.

[43] D.S. MacFarlane, (Hastings On Hudson, NY), D.K. MacFarlane, (Hastings On Hudson, NY), \& F.W. Billmeyer, (Schenectady, NY). Method and instrument for selecting personal compatible colors. (1936). United States Patent 5313267. Available from http://www.freepatentsonline.com/5313267.html.

[44] Y.V. García-Tejeda, C. López-González, J.P. Pérez-Orozco, R. Rendón-Villalobos, A. Jiménez-Pérez, E. Flores-Huicochea, J. Solorza-Feria, C.A. Bastida, Physicochemical and mechanical properties of extruded laminates from native and oxidized banana starch during storage, LWT - Food Sci. Technol. 54 (2013) 447-455.

[45] P. Molyneux, The use of the stable free radical diphenylpicrylhydrazyl (DPPH) for estimating antioxidant activity, Songklanakarin J. Sci. Technol. 26 (2004) 211-219.

[46] A.G. Ponce, R. Fritz, C. Del Valle, S.I. Roura, Antimicrobial activity of essential oils on the native microflora of organic Swiss chard, LWT Food Sci. Technol. 36 (2003) 679-684.

[47] D. Merino, R. Ollier, M. Lanfranconi, V. Alvarez, Preparation and characterization of soy lecithin-modified bentonites, Appl. Clay Sci. 127 (2016) 17-22.

[48] C.M. Ouellet-Plamondon, J. Stasiak, A. Al-Tabbaa, The effect of cationic, nonionic and amphiphilic surfactants on the intercalation of bentonite, Colloid. Surf. A 444 (2014) 330-337.

[49] J. Zhang, R.K. Gupta, C.A. Wilkie, Controlled silylation of montmorillonite and its polyethylene nanocomposites, Polymer 47 (2006) 4537-4543.

[50] A. Di Gianni, E. Amerio, O. Monticelli, R. Bongiovanni, Preparation of polymer clay mineral nanocomposites via dispersion of silylated montmorillonite in a UV curable epoxy matrix, Appl. Clay Sci. 42 (2008) 116-124.

[51] B. Wicklein, M. Darder, P. Aranda, E. Ruiz-Hitzky, Bio-organoclays based on phospholipids as immobilization hosts for biological species, Langmuir 26 (2010) 5217-5225.

[52] J. Zhu, Y. Qing, T. Wang, R. Zhu, J. Wei, Q. Tao, P. Yuan, H. He, Preparation and characterization of zwitterionic surfactant-modified montmorillonites, J. Colloid. Interf. Sci. 360 (2011) 386-392.

[53] M.G. Neumann, F. Gessner, A.P.P. Cione, R.A. Sartori, C.C.S. Cavalheiro, Interaction between dyes and clays in aqueous suspension, Quím. Nova 23 (2000) 818-824.

[54] B. Öztop, T. Shahwan, Modification of a montmorillonite-illite clay using alkaline hydrothermal treatment and its application for the removal of aqueous $\mathrm{Cs}^{+}$ions, J. Colloid. Interf. Sci. 295 (2006) 303-309.

[55] R. Ruiz, C. Blanco, C. Pesquera, F. González, I. Benito, J.L. López, Zeolitization of a bentonite and its application to the removal of ammonium ion from waste water, Appl. Clay Sci. 12 (1997) 73-83.

[56] J.M. Jay, Modern Food Microbiology, fifth ed., Chapman \& Hall Pub, New York, 1996.

[57] D.A. D'Amico, R.P. Ollier, V.A. Alvarez, W.F. Schroeder, V.P. Cyras, Modification of bentonite by combination of reactions of acid-activation, silylation and ionic exchange, Appl. Clay Sci. 99 (2014) 254-260.

[58] V.T. Farmer, J.D. Russell, The infra-red spectra of layer silicates, Spectrochim. Acta 20 (1964) 1149-1173.

[59] J. Madejova, P. Komadel, Baseline studies of the clay minerals society source clays: infrared methods, Clay. Clay. Min. 49 (2001) 410-432.

[60] P.S. Nayak, B.K. Singh, Instrumental characterization of clay by XRF, XRD and FTIR, B. Mater. Sci. 30 (2007) 235-238.

[61] K. Bahranowski, A. Gaweł, A. Klimek, A. Michalik-Zym, B.D. Napruszewska, M. Nattich-Rak, M. Rogowska, E.M. Serwicka, Influence of purification method of Na-montmorillonite on textural properties of clay mineral composites with $\mathrm{TiO}_{2}$ nanoparticles, Appl. Clay Sci. 140 (2017) 75-80.

[62] D. de Ligny, E. Guillaud, H. Gailhanou, P. Blanc, Raman spectroscopy of adsorbed water in clays: first attempt at band assignment, Proced. Earth Planet. Sci. 7 (2013) 203-206.

[63] A. Ivanoska-Dacikj, G. Bogoeva-Gaceva, S. Rooj, S. Wießner, G. Heinrich, Fine tuning of the dynamic mechanical properties of natural rubber/carbon nanotube nanocomposites by organically modified montmorillonite: a first step in obtaining high-performance damping material suitable for seismic application, Appl. Clay Sci. 118 (2015) 99-106.

[64] J. Kabilaphat, N. Khaorapapong, K. Saito, M. Ogawa, Preparation of metal sulfide mixtures in montmorillonite by solid-solid reactions, Appl. Clay Sci. 115 (2015) 248-253.

[65] H. Sun, T. Peng, B. Liu, H. Xian, Effects of montmorillonite on phase transition and size of $\mathrm{TiO}_{2}$ nanoparticles in $\mathrm{TiO}_{2} /$ montmorillonite nanocomposites, Appl. Clay Sci. 114 (2015) 440-446.

[66] J. Tokarský, P. Peikertová, L. Kulhánková, K. Mamulová Kutláková, L. Neuwirthová, V. Matějka, V. Stýskala, P. Čapková, Functional nanostructures of montmorillonite with conducting polyaniline, Clay Min. 50 (2015) $341-351$.

[67] J.M. Obón, M.R. Castellar, M. Alacid, J.A. Fernández-López, Production of a red-purple food colorant from Opuntia stricta fruits by spray drying and its application in food model systems, J. Food Eng. 90 (2009) 471-479.

[68] W.J. Steyn, Prevalence and functions of anthocyanins in fruits, in: K. Gould, K. Davies, C. Winefield (Eds.), Anthocyanins Biosynthesis, Functions, and Applications, Springer, New Zealand, 2009, pp. 85-87.

[69] A.S. Abreu, M. Oliveira, A. de Sá, R.M. Rodrigues, M.A. Cerqueira, A.A. Vicente A.V. Machado, Antimicrobial nanostructured starch based films for packaging, Carbohydr. Polym. 129 (2015) 127-134. 